\title{
Effect of Pretreatment Process on the Adhesion and Corrosion Resistance of Chromium-Carbon Coatings Deposited on Copper Substrates
}

\author{
Hung-Hua Sheu ${ }^{1, *}$, Yuan-Rong Chen ${ }^{1}$, Tzu-Te Lin ${ }^{2}$, Ming-Der Ger ${ }^{1, *}$ \\ ${ }^{1}$ Department of Chemical and Materials Engineering, Chung Cheng Institute of Technology, National \\ Defense University, Taoyuan City, Taiwan \\ ${ }^{2}$ Graduate School of National Defense Science, Chung Cheng Institute of Technology, National \\ *E-mail: shhccit@gmail.com, mingderger@gmail.com
}

doi: $10.20964 / 2019.04 .52$

Received: 11 December 2018 / Accepted: 20 February 2019 / Published: 10 March 2019

In this work, the copper substrates are pretreated by chemical polishing and mechanical polishing to change their surface roughness. Then, the effects of the substrate surface roughness on adhesion and corrosion resistance of chromium-carbon coatings electrodeposited onto copper substrates are investigated. The surface roughness of chromium-carbon coatings are analyzed by a surface roughness measuring system. An ELCOMETER-106 adhesion tester is utilized to measure the adhesion strength of chromium-carbon thin films electrodeposited on copper substrates. The highest adhesion strength of 8.1 MPa is obtained for chromium-carbon thin film electrodeposited on mechanically polished copper substrate. The electrochemical behavior tested by potentiodynamic for two scans in $3.5 \mathrm{wt} . \% \mathrm{NaCl}$ solution shows that the chromium-carbon thin film electrodeposited on mechanically polished copper substrate exhibits better corrosion resistance than that of chromium-carbon coating electrodeposited on unpolished and chemically polished substrates. The chromium-carbon thin film electrodeposited on mechanically polished copper substrate with the least roughness has the relatively highest corrosion resistance and adhesion force and this can be attributed to the chromium-carbon thin film has a crackfree structure when the copper substrate is polished mechanically.

Keywords: chromium-carbon thin films, adhesion strength, mechanical polishing, chemical polishing

\section{$\underline{\text { FULL TEXT }}$}

(C) 2019 The Authors. Published by ESG (www.electrochemsci.org). This article is an open access article distributed under the terms and conditions of the Creative Commons Attribution license (http://creativecommons.org/licenses/by/4.0/). 